\title{
APONTAMENTOS SOBRE O CONCEITO DE JOGO A PARTIR DE SUA PRÁTICA NO ENSINO DE FILOSOFIA
}

\section{APPOINTMENTS ABOUT THE CONCEPT OF GAME FROM ITS PRACTICE IN THE TEACHING OF PHILOSOPHY}

\author{
Taís Silva Pereira ${ }^{1}$ \\ Recebido em: 05/2018 \\ Aprovado em: 07/2018
}

\begin{abstract}
Resumo: O presente artigo é o início de uma pesquisa em andamento e tem como ponto de partida as atividades realizadas com jogos nas aulas de filosofia para o ensino médio do CEFET/RJ e, notadamente, no projeto de extensão "A filosofia na construção de jogos", cadastrado na mesma instituição desde 2013. Com efeito, a prática de produção de jogos - enquanto parte da avaliação bimestral na disciplina e também como ação de divulgação do saber filosófico na comunidade escolar - colocou em questão a produção coletiva de recursos didáticos alternativos para as aulas de filosofia no ensino médio mediante a participação dos envolvidos, bem como possibilidades de avaliar os produtos elaborados durante o processo de sua construção e após sua culminação. As tentativas de resposta a estas questões levaram à necessidade de uma consideração mais aprofundada sobre a atividade de jogar e seu uso educacional. Desta forma, ao se avançar na discussão sobre o uso de jogos como um material proveitoso para o ensino-aprendizagem, propõese analisar de forma preliminar o conceito de jogo, tendo em vista sua prática no ensino de filosofia. Para esta tarefa, serão abordados alguns aspectos conceituais presentes na atividade de jogar, os quais apontam para uma possível aproximação com a filosofia. Assim, caberá analisar: (1) o espaço demarcado pelo jogo através do lúdico; (2) a ordenação própria aberta aos participantes de um jogo, analisados por Johan Huizinga. E, em seguida, os conceitos de (3) espaço comum e (4) articulação, desenvolvidos pelo filósofo Charles Taylor também serão examinados. A hipótese inicial deste trabalho é de que o jogo pode ter um tratamento filosófico que dê suporte ao seu uso no processo de ensino-aprendizagem, sem se restringir a uma ferramenta de facilitação na transmissão de conteúdos a serem adquiridos.

Palavras-chave: Jogos; Filosofia; Ensino-aprendizagem; Recursos didáticos.
\end{abstract}

\begin{abstract}
The present article is the beginning of a research in progress and it has as a starting point the activities realized with playing games in the high school philosophy's classes at CEFET/RJ and, notably, with the extention project "Philosophy in building games", which is registered at the same institution since 2013. In effect, the games production practice - as part of bimonthly evaluation in the discipline and also as the disseminative action of philosophical knowledge in the school community - puts into question the collective production of alternative didactic materials for the high schools philosophy's classes throughout the participation of all concerned, and also the possibilities to evaluate the ellaborated products thorough the process of its construction and its culmination. The answer to attempt these questions brought the necessity of profound consideration about playing and its educational use. In this way, to advance the discussion about the use of games as a profitable material for the teaching-learning process, it is proposed to preliminarily analyse the game's concept, in view of its practice in the teaching of philosophy. For this task, some conceptual aspects present in the game will be approached, which
\end{abstract}

1 Centro Federal de Educação Tecnológica Celso Suckow da Fonseca - CEFET/RJ. Email: pereira_tais@yahoo.com.br 
take a possible aim of proximity with philosophy. So, the following will be analysed: (1) the space demarcated by game through playing; (2) the own order that is opened to participants of a game, both analysed by Johan Huizinga. After that, the concepts of (3) common space, and (4) articulation, developed by the philosopher Charles Taylor, will be examined too. The initial hypothesis in this work is that games can have a philosophical treatment which gives support to their use in the teaching-learning process, and won't be restricted to a facilitation tool in the transmition of contents to be acquired.

Keywords: Games; Philosophy; Teaching-learning; Didactic materials.

\section{Introdução}

Entre os anos de 2010 e 2015 foram realizadas atividades com produção de jogos integrados à filosofia no Campus Nova Iguaçu², localizado na Baixada Fluminense do Estado do Rio de Janeiro, do Centro Federal de Educação Tecnológica Celso Suckow da Fonseca CEFET/RJ. O recurso de jogos para o ensino de filosofia com turmas de ensino médio teve, neste período, um duplo direcionamento: a introdução da elaboração de jogos enquanto forma de avaliação bimestral e também a divulgação da filosofia fora da sala de aula, com o projeto de extensão intitulado "A filosofia na construção de jogos", cadastrado na mesma instituição no ano de 2013. Em ambos os casos, a questão que permeava os planejamentos dizia respeito à elaboração de materiais didáticos alternativos para as aulas de filosofia no ensino médio.

Sobre um primeiro aspecto, a elaboração de jogos como parte da média bimestral se propunha, a partir de 2010, explorar outras formas de apropriação nas aulas de filosofia que não fossem centralizadas somente em produções textuais. Assim, após leituras e discussões acerca do conteúdo tratado em sala, as turmas poderiam se organizar em grupos para tratar as problematizações levantadas ao longo do bimestre sob a forma de jogos, os quais seriam usufruídos por todos os estudantes. Embora o formato do jogo fosse livre, ele deveria ser pensado para jogadores não habituados a aulas de filosofia. Assim, isto garantiria que o desenvolvimento da produção não fosse restrito a um quiz, formatado na elaboração de perguntas e respostas sobre o conteúdo estudado em sala. O principal objetivo neste momento foi acompanhar o modo como os alunos tratavam elementos filosóficos na consecução de um jogo (um registro não filosófico) para um público que não tivesse contato com textos filosóficos ou conceitos específicos levantados ao longo da história da filosofia.

\footnotetext{
2 A partir de 2017, as atividades foram redirecionadas para o Campus Maracanã e são realizadas nos mesmos moldes dos anos anteriores.
} 
Isto significaria, pois, um exercício de tradução ${ }^{3}$ do texto e das discussões promovidas pela turma para as regras de um jogo viável, ou seja, que pudesse ser jogado. Tal processo poderia ser conferido, assim, no dia da apresentação, quando a turma se revezaria para jogar os materiais produzidos pelos seus próprios colegas. Neste dia, o jogo era acompanhado de seu respectivo manual, que explicaria a sua funcionalidade, e igualmente de uma justificativa para a escolha da mecânica, tendo em vista o tema tratado.

Tal dinâmica oferecia, pois, um duplo viés: ao mesmo tempo em que contava com uma produção coletiva de produção e avaliação entre pares (os estudantes, ao jogarem, testavam a viabilidade dos materiais - jogabilidade - como parte dos critérios de avaliação), igualmente tornava as problematizações realizadas o ponto de partida para possíveis soluções através do lúdico. Ao longo das apresentações ficava mais claro que os jogos apresentados pelos estudantes ultrapassavam uma transmissão de informação na medida em que as partidas abriam espaços de discussão e debate, só possíveis na experiência do próprio jogo.

Embora essas avaliações fossem proveitosas tanto para as turmas quanto para a professora, era impossível acompanhar o processo de elaboração - justamente quando as possibilidades de tradução do registro discursivo para o lúdico ganham vida. A fim de suprir tal lacuna, criou-se em 2013 o projeto de extensão "A filosofia na construção de jogos", cujo objetivo é produzir anualmente um jogo para ser apresentado à comunidade escolar e igualmente ser utilizado nas aulas de filosofia, assumindo o papel de recurso didático. Por isso, o projeto também apresenta dois direcionamentos, quais sejam, a divulgação da filosofia em uma escola pública e técnica, bem como o protagonismo estudantil - ao se elaborar recursos alternativos para serem utilizados por outros alunos em sala de aula. Desde 2013, foram produzidos pelos alunos e professora cinco jogos no Campus de Nova Iguaçu e um no Campus Maracanã em 2017 . Durante todo o processo, os participantes estão em igualdade de condições, como coautores dos percursos e decisões: desde a definição do tema e mecânica

\footnotetext{
3 Embora não seja tema deste trabalho, o processo de tradução, tomado em sentido amplo, é uma parte importantíssima para as aulas de filosofia, em geral e, em particular, nos trabalhos com jogos, na medida em que põe em relevo os elementos a serem apropriados, enquanto processo, na apresentação de diferentes narrativas. Aqui, basta apontar que toda a tradução parte de uma "tradição viva", como afirma Porta (2014, p. 100), isto é, é encarnada historicamente em práticas e crenças - não apenas das ideias desenvolvidas pelo texto a ser traduzido, mas igualmente por quem o lê.

${ }^{4}$ Todos os jogos foram apresentados na Semana de Extensão do CEFET/RJ e foram eventualmente levados a outras escolas. Dentre os jogos produzidos no período das atividades realizadas no Campus Nova Iguaçu destacam-se um jogo de tabuleiro que aborda a introdução à filosofia enquanto experiência de pensamento compartilhada, o "Filostecas"; um RPG narrado destinado a explorar diferentes narrativas míticas, não só de origem grega, o "Mitologias, o jogo" e um jogo de cartas que aborda a ética a partir de seus dilemas, o "Em busca da justiça". Em 2017, foi apresentado o jogo de tabuleiro com cartas, o "Aisthesis", voltado para o tema da beleza e padrões de gosto, na área da estética filosófica, com o recurso de imagens.
} 
até sua finalização e avaliação. Com efeito, a prática ao longo destes anos aponta que o ganho não é apenas de caráter atitudinal - saber acolher e oferecer argumentos mediante razões; apresentar autonomia de pesquisa; trabalhar em grupo e deliberar coletivamente; horizontalizar as discussões, por exemplo - mas igualmente um espaço de elaboração de problemas e de levantamento conceitual diverso, não se resumindo à transposição de conteúdos.

Desta forma, a partir das atividades em sala de aula e do bom desenvolvimento que vem tendo o projeto de extensão, houve a necessidade de se refletir de forma mais aprofundada sobre a atividade de jogar com fins de avaliação, divulgação e recurso didático que não fossem restritos ao uso instrumental de mecânicas de jogos (genericamente, regras e objetivos de jogos específicos) para a transmissão de conteúdos. E, a fim de empreender tal tarefa, inicia-se uma pesquisa sobre o conceito de jogo a partir do ensino de filosofia.

\section{Apontamentos iniciais acerca do conceito de jogo}

A tentativa de aliar diversão e aprendizado não é uma novidade. Facilmente se encontram no mercado ou no meio educacional, brincadeiras e jogos desenvolvidos para o aprendizado, de forma mais ou menos intencional. Com efeito, esse movimento não é isolado e vem crescendo, especialmente na virada do século, com o uso de aparelhos eletrônicos e aplicativos de amplo acesso. Nesta onda pela valorização dos jogos, surge o fenômeno da gameficação (DETERDING, 2001), isto é, a utilização de mecânicas de jogos para tarefas de "não-jogo". Trata-se, assim, da motivação à realização de alguma atividade ou solução de algum problema real, cujo processo não se torne cansativo ou tedioso para o agente porque este se dá na experiência que o jogo oferece. Desta forma, o êxito garante recompensas (mudança de nível, acúmulo de pontos) e o fracasso alguma espécie de punição (a não continuidade do jogo, a demora de sua finalização). Em outras palavras, há a tentativa de garantir o meio divertido, que confira bem-estar, para se atingir um fim determinado - que pode ir desde o cumprimento das rotinas diárias até o aumento do vocabulário em língua estrangeira. Através da gameficação pode-se, inclusive, apresentar conceitos e questões levantados por determinadas escolas e correntes na história da filosofia. Contudo, este seria o melhor modo de estudar filosofia na educação básica?

A pesquisa inicial que aqui se apresenta responde negativamente a esta pergunta. Isto significa assumir o ensino de filosofia além da apresentação de pensadores e conceitos 
elaborados ao longo de sua história. Antes, isto só teria sentido no interior do quadro de uma prática e experiências específicas, em sua relação com o conhecimento, diferenciando-se da obtenção de informação, tal como propugna Larrosa:

Este é o saber da experiência: o que se adquire no modo como alguém vai respondendo ao que vai lhe acontecendo ao longo da vida e no modo como vamos dando sentido ao acontecer do que nos acontece. No saber da experiência não se trata da verdade do que são as coisas, mas do sentido ou do sem-sentido do que nos acontece. (LARROSA, 2016, p. 32)

As atividades desenvolvidas no CEFET/RJ já partem de tal defesa e, por conseguinte, se encaminham para outro tratamento conferido ao jogo, enquanto problema filosófico, tendo em vista as possibilidades de experiência nas aulas de filosofia. Mais do que um desfile das diferentes teorias, pretende-se pensá-las no embate de responder da melhor forma as problematizações que as nutre.

As preocupações levantadas na introdução levam, portanto, à investigação filosófica sobre a especificidade da atividade de jogar e suas implicações para o ensino de filosofia, sobretudo no ensino médio. E, a fim de tecer alguns apontamentos da pesquisa que se inicia, se recorrerá ao pensamento de Johan Huizinga, especificamente seu texto Homo ludens, e ao filósofo Charles Taylor, no que diz respeito aos conceitos de espaço comum e articulação.

Para o primeiro (2012, p. 4ss), mesmo que o jogo não seja exclusividade da ação humana, ao se expressar pelo divertimento (o prazer), ele é constitutivo de culturas. Assim, o jogo não é um elemento no interior da cultura, mas a engendra. Está associado a diversos rituais que integram comunidades e as mantêm vivas. Ele é, sobretudo, uma função significante, ou seja, confere sentido às práticas compartilhadas. Isto quer dizer que o jogo não possui uma finalidade externa, não se restringe a um meio. É desta forma que Huizinga faz questão de se distanciar de certas análises de caráter biológico e psicológico, na medida em que ambos não considerariam o jogo como atividade autônoma, mas o limitariam ao desenvolvimento de determinadas capacidades: sensação de bem-estar, cooperação e sociabilidade, gasto de energia, dentre outros.

Por isso, o pensador se encaminha para um tratamento da natureza do jogo enquanto tal. Segundo ele, é possível fazê-lo através da enumeração de algumas características formais. Resumidamente, 
absolutamente obrigatórias, dotado de um fim em si mesmo, acompanhado de um sentimento de tensão e de alegria e de uma consciência de ser diferente da 'vida cotidiana'. (HUIZINGA, 2012, p. 34)

A despeito das críticas dirigidas a Huizinga quanto a sua falta de sistematização e classificação dos jogos (CAILLOIS, 1990) ou de sua grande abrangência (DUFLO, 1997), a definição proposta pelo pensador holandês parece ser um bom início de análise. Assim, ao elencar as características formais que perfazem o conceito de jogo, destacam-se quatro elementos, são eles: 1. O jogo é uma atividade voluntária é, portanto, livre (o jogo depende da adesão dos participantes que se deixam submeter por suas regras); 2. O jogo não é a vida corrente, nem a vida real (ele não se confunde com a rotina ou cotidiano; antes, circunscreve os limites do divertimento sem deixar de ser sério); 3. O jogo é caracterizado pelo isolamento e pela limitação (os jogos funcionam a partir de determinada configuração, eles têm, portanto, uma duração e um espaço - ainda que seja o virtual); 4. O jogo cria ordem e é ordem (porque se constitui por determinadas regras de orientação - que não são de ordem ética ou mesmo estética - criando redes de integração, tal como uma comunidade).

Dois dos quatro pontos supracitados interessam a presente exposição, cujo horizonte é o ensino de filosofia no ensino médio. São eles: a autonomia e seriedade do jogo (ponto 2) e o fato de o jogo criar e ser ordem (ponto 4). As demais características são importantes, mas não serão objetos de análise neste momento.

\section{Sobre a seriedade do lúdico e sua configuração}

Quanto ao ponto referente à autonomia e seriedade do jogo, a atividade de jogar destaca-se da vida corrente. Uma criança sabe diferenciar o faz de conta da realidade, mas isto não significa que o divertimento infantil seja menor ou não sério. De forma análoga, jogos de RPG (Role Playing Game), de interpretação de papeis, no interior de uma narrativa em constante construção, não são encarados pelos jogadores como mero passatempo. A diferença entre o lúdico e a não-seriedade é importante para o Huizinga justamente porque ao jogo pertence uma configuração específica que ultrapassa o campo das necessidades, dado que ele tem fim em si mesmo. Não é, portanto, por uma finalidade biológica, cognitiva, ou psicológica fundada em capacidades que o lúdico se apresenta, e sim um modo de estar e compreender a realidade, só expressos quando se joga. 
Todo jogo é capaz, a qualquer momento, de absorver inteiramente o jogador. Nunca há um contraste bem nítido entre ele e a seriedade, sendo a inferioridade do jogo sempre reduzida pela superioridade de sua seriedade. Ele se torna seriedade e a seriedade, jogo. (HUIZINGA, 2012, p. 11).

Segundo Huizinga, há uma "consciência de ser diferente da vida cotidiana", uma espécie de consciência lúdica (DUFLO, 1997, p. 41), que demarca e diferencia espaçotemporalmente o jogo dos demais domínios da vida, acompanhado de um "sentimento de tensão e de alegria”. Esta tensão, o sentimento de incerteza diante das partidas, promove em maior ou menor grau (compare-se, por exemplo, um jogo de azar com uma partida de xadrez) o caráter indeterminado do jogo quanto ao seu sucesso. Jogar é assumir as possibilidades que se abrem no interior do próprio jogo, por isso seu caráter autônomo. Por autonomia entendese, então, o fato de o jogo encerrar um sentido em sua própria atividade, indo além de um interesse ulterior, expressando seu caráter desinteressado. Afastar-se da vida cotidiana não significa, porém, um mero intervalo, vinculado à não-ocupação. Para Huizinga, embora não seja restrito à subsistência, o jogo carrega uma função significante, tocando a vida em geral e é nesta medida em que ele é necessário:

Ornamenta a vida, ampliando-a, e nessa medida torna-se uma necessidade tanto para o indivíduo, como função vital, quanto para a sociedade, devido ao sentido que encerra, à sua significação, a seu valor expressivo, a suas associações espirituais e sociais, em resumo como função cultural. Dá satisfação a todo o tipo de ideais comunitários. (HUIZINGA, 2012, p. 12)

É possível afirmar, a partir do pensador holandês, que a consciência lúdica reafirma laços comunitários e aponta para um propósito comum, contribuindo para uma sobrevivência simbólica porque diz respeito também a um processo de aprendizagem, ao ser realizado repetidamente - assim como nos rituais, o tempo é sempre a experiência da atividade, não a temporalidade cronológica. Ser absorvido pelo jogo possui, então, um duplo movimento: insere os participantes em uma atividade por sentimento de tensão e alegria e, ao mesmo tempo, promove a abertura de uma compreensão compartilhada através de uma prática. A relação entre o lúdico e a seriedade abre caminho para considerações acerca de como se orientar em um campo específico, levando em consideração aspectos além do puramente cognitivo para o ensino-aprendizagem. Com efeito, isto nos leva ao segundo ponto a ser explorado, qual seja, o fato de o jogo criar ordem e ser ordem (ponto 4).

A configuração do jogo é dada por suas regras. Para jogar é preciso que o participante as reconheça e se deixe submeter por elas. Huizinga (2012, p. 13) afirma que "o jogo exige 
uma ordem suprema e absoluta: a menor desobediência a esta 'estraga o jogo', privando-o de seu caráter próprio e de todo e qualquer valor". Assim, é através do estabelecimento das regras que se define o campo do jogo e também do não-jogo.

Por um lado, ao ser ordem, o jogo delimita seu domínio da vida cotidiana e oferece um espaço específico para que aquela atividade faça sentido. Assim, não se pode jogar damas com as regras do xadrez porque a existência de ambos se constitui através de suas respectivas regras, as quais apontam para o que pode e o que não pode ser feito, não permitindo discussão. No máximo, transformar as regras é criar outro jogo ou impedir que aquele seja vivenciado. Todavia, essa delimitação é sempre temporária porque diz respeito ao tempo e espaço da prática do jogo e por isso é sempre um terreno instável, capaz de ser facilmente quebrado: seja pelo não reconhecimento das regras (que pode ser pela trapaça ou por não aceitar o andamento do jogo), seja por uma ruptura externa (uma interrupção que leve os jogadores a voltarem para a vida cotidiana).

Por outro lado, o jogo também cria ordem, ou seja, delimita o campo de atuação dos jogadores. Ao ingressarem em uma partida, os envolvidos precisam se orientar dentro do que for permitido, promovendo modos de conduta que, ao mesmo tempo, não são sufocados pelas regras. Embora elas circunscrevam a própria atividade do espaço do "não-jogo", com suas interdições e fronteiras, permitem em alguma medida a novidade. Uma boa jogadora é aquela que não apenas conhece as regras, mas as articula, criando jogadas inesperadas e, não raras as vezes, abrindo possibilidades até então desconhecidas. Em outras palavras, ela articula as ações no espaço previamente determinado pela existência do jogo, mas não totalmente fixo. Note-se que isto não acarreta na destruição do jogo, mas na exploração de seus limites.

Criar e ser ordem são concomitantes: a delimitação do espaço convida o jogador a executar determinadas ações. E, ao estar disposto a participar, ele se encaminha por uma experiência de tensão, na qual sempre se pode fracassar. Para Huizinga, estes elementos são encontrados em diversas manifestações culturais, especialmente nos rituais. O chamado "círculo mágico", espaço delimitado pelo jogo, retira os envolvidos no processo da vida corrente, sem excluí-los, posto que a função significante do jogo está vinculada a um propósito comum que se estende, em alguma medida, para o domínio do não-jogo: "Dá satisfação a todo o tipo de ideais comunitários" (HUIZINGA, 2012, p. 12).

\section{Espaço comum e articulação:}


Assumir as caracterizações de Huizinga também implica considerar este espaço enquanto uma comunidade de participantes que assumem um propósito comum. E é neste sentido que os conceitos de espaço comum e articulação, desenvolvidos no pensamento de Taylor, merecem destaque. Em artigo dedicado ao conceito de esfera pública, o filósofo canadense faz uma distinção importante para os propósitos da pesquisa aqui apresentada.

Segundo ele (2000, p. 279-280), a esfera pública é um espaço comum porque se move a partir do horizonte de uma comunidade, isto é, os participantes possuem propósitos compartilhados, apesar de suas diferentes motivações, não se restringindo à soma de interesses individuais. Diz Taylor:

Podemos falar de 'espaço comum' quando as pessoas se reúnem num ato concentrado para algum propósito, seja ele o ritual, a fruição de um jogo, a conversação, a celebração de um evento importante. Seu foco é comum, em vez de meramente convergente, por ser parte daquilo que é comumente compreendido, que as pessoas estão presentes com vistas ao objeto comum, ou propósito comum, juntas, em vez de cada pessoa simplesmente estar, a partir de si mesma, preocupada apenas com a mesma coisa. (TAYLOR, 2000, p. 280)

Convém sublinhar alguns pontos acerca da citação precedente. $\mathrm{O}$ primeiro deles diz respeito ao caráter prático do espaço comum, ele envolve algum tipo de engajamento. Todos os exemplos oferecidos pelo pensador apontam para uma ação concentrada, realizada no interior de certos limites, os quais demarcam também a atividade propriamente dita. O jogo, portanto, é um tipo de atividade que emerge de um espaço comum, no qual as regras estão postas. Mesmo um jogo solitário, como paciência ou o quebra-cabeça, pertencem a um espaço comum, na medida em que são conhecidos pela ordenação própria de seus respectivos jogos. A presença, segundo elemento importante, não está restrita à permanência física desta atividade.

Ao avançar na discussão, Taylor diferencia espaços comuns em duas categorias distintas, mas que se interpenetram. São eles: os espaços metatópicos e os espaços tópicos. Enquanto os primeiros são eminentemente políticos porque transcendem o espaço físico, constituindo o que entendemos por esfera pública, os segundos se caracterizam, sobretudo, pela presença comum, pela reunião de pessoas (física ou virtual), seja em um ritual, em uma partida de futebol, em uma apresentação musical ou em um jogo. Jogos, portanto, manifestam comunidades de participantes que possuem um propósito comum: jogar. É neste espaço comum tópico, delimitado pela ordem reconhecida, que leva a atividade propriamente dita ao 
seu limite. Embora ele possua níveis mais íntimos (uma conversação, ou ainda jogos solitários) ou mais amplos (um ritual, ou competições), não é a soma de interesses privados. Antes, é a possibilidade de realização desta atividade que a insere no interior de uma comunidade. A presença se faz necessária porque o jogo só se constitui enquanto atividade de indivíduos, que elaboram suas condutas a partir das regras vigentes do jogo. Neste sentido, ela demanda uma compreensão comum.

O conceito de compreensão comum, proposto por Taylor, aponta para um tipo específico de comunidade, que se afasta da noção de somatório de interesses particulares visando um fim específico. Isto porque a comunidade enquanto convergência de interesses e preocupações pessoais leva a dois caminhos que o filósofo canadense pretende evitar: o atomismo e um pressuposto utilitário. Ambos estão intricados e dizem respeito à noção comunitária pensada a partir de indivíduos cujos interesses específicos podem ser mais bem satisfeitos em grupo. A comunidade seria, então, o meio para a satisfação de desejos individuais, não se confundindo com um espaço comum. Seu pertencimento é convergente. Ao contrário deste enfoque, Taylor pensa a compreensão comum como parte daquilo que já sempre se assume em uma atividade, o que se supõe para que a ação faça sentido. Na realização de um jogo, assim como em uma dança e conversação, há um ritmo próprio, uma harmonia que demanda uma conexão entre os participantes, permitindo que a atividade ocorra. Há uma concomitância entre ação dos agentes e este pano de fundo, na medida em que um elemento reafirma o outro em sua realização: só se pode agir de um modo e não de outro porque há um espaço comum interação, o qual abre a possibilidade das ações que expressam esta atividade. No caso específico do jogo, este espaço comum é, pois, o próprio corpo de regras que lhe dá vida. E, se as regras não anulam o inesperado, mas antes o convidam, já que um bom jogo é marcado por tensões, conflitos, mais ou menos profundos, a articulação deve ser considerada.

Articulação é um conceito importante, perpassando toda a obra de Taylor. É definida por tornar manifesto aquilo que está obscuro (por parecer óbvio, por depender de conexões não evidentes), sendo o exercício de trazer à tona a base implícita das nossas compreensões comuns:

articulações são tentativas de formular o que é inicialmente incipiente, ou confuso, ou mal formulado. Mas, este tipo de formação ou reformulação não deixa seu objeto inalterado. Oferecer certa articulação é conformar nosso 
discernimento do que nós desejamos ou o que nós assumimos como importante em certo sentido..$^{5}$ (TAYLOR, 1985, p. 36, tradução livre)

Primeiramente, articular é um verbo de sucesso, ou seja, pode-se ou não fracassar na tentativa de expressar as conexões possíveis implícitas nos discursos e ações (ela pode ser mais ou menos adequada, mais ou menos distorcida, melhor ou pior). Em segundo lugar, tal expressão envolve o que se é. Em outros termos, é inseparável da condição e das experiências vivenciadas pelo agente, por isso é um tipo de explicação que demanda sua situação e o que se espera dela, lhe é constitutiva. Tal constituição, por conseguinte, leva em consideração uma auto-interpretação do articulador, envolvendo avaliações qualitativas de si e de si em relação ao objeto investigado. Finalmente, ao alterar não apenas o objeto, mas o modo de esclarecêlo, as articulações mostram novas possibilidades de formulação a fim de dar sentido às ações e explicações que se abrem a partir de um campo comum.

Para Taylor (1985, p. 41), a filosofia é um saber articulador na medida em que trabalha conceitualmente e, ao fazê-lo, diz respeito ao modo como esta prática se situa diante das questões e formas de abordagem. A investigação filosófica se inicia com uma questão a partir de um campo compartilhado (pode-se chamar de tradição, de mundo da vida, etc.), a qual demanda um esclarecimento, a identificação acerca do que está na base do problema. A tentativa de resposta repousa no horizonte de tornar manifesto os conceitos que dão suporte à questão levantada, e pretende transformar de alguma maneira o tratamento ou mesmo o encaminhamento para a questão inicial. Este processo é inseparável da experiência do filósofo que torna este caminho o seu caminho. Talvez a caminhada leve-o a iluminar questões e levantar inovações conceituais que não estavam previstas inicialmente, tocando uma área da experiência humana da qual ele compartilha.

Resta saber, agora, de que forma este levantamento conceitual do pensamento de Huizinga e de Taylor pode abrir um caminho para se pensar a atividade do jogo de forma proveitosa nas aulas de filosofia. Primeiro, vale ressaltar, não há a pretensão de fazer do jogo $a$ metodologia para o ensino de filosofia na educação básica. Muito menos, não se tem a expectativa de uma gameficação do conhecimento, isto é, que a diversão seja imperativa no processo de conhecer, no sentido de afirmar uma relação causal entre ambos. Antes, a motivação da pesquisa está enraizada na possibilidade de se oferecer um tratamento filosófico para o jogo (enquanto atividade) para o ensino de filosofia, a qual é pensada desde uma

\footnotetext{
5 No original: “[...] articulations are attempts to formulate what is initially inchoate, or confused, or badly formulated. But this kind of formation or reformulation does not leave its object unchanged. To give a certain articulation is to shape our sense of what we desire or what se hold important in a certain way".
} 
experiência específica, que tem em vista a compreensão de si e de sua relação com o que acontece ao redor.

Segundo Duflo (1999), a consideração filosófica a respeito do jogo acompanha as preocupações sobre a formação humana e a valorização da infância neste percurso, situando uma discussão mais sistematizada a partir dos séculos XVIII e XIX, culminando com a valorização do jogo a partir do pensamento de Schiller. Até então, afirma o pensador francês, o fenômeno lúdico aparece nos textos filosóficos marginalmente, no interior de duas principais preocupações: relativas à conduta humana e ao desenvolvimento do espírito. No primeiro caso, funcionaria como uma forma de propiciar a boa convivência, ou ainda circunscrever os limites de sua atuação na vida humana, evitando excessos (o vício do jogo). Em todo o caso, "deve ser uma atividade menor, cujo verdadeiro significado é totalmente negativo: é o momento indispensável de não-trabalho. Só é atividade em aparência, pois não pode ser sadiamente concebido a não ser como repouso de atividade" (DUFLO, 1999, p. 21). No segundo caso, situado especialmente no século XVII, ainda que o jogo seja uma atividade, ela é em menor grau por se tratar de um exercício das capacidades humanas para o seu desenvolvimento, o jogo ensinaria, assim, a pensar. Seu interesse está, pois, subordinado a uma investigação sobre o entendimento humano:

De maneira geral, o jogo é uma escola, pois pressupõe e estimula a atenção, qualidade essencial do espírito inventivo que só o é porque é primeiro espírito atento. Ora, o risco, que constitui boa parte do prazer lúdico, obriga precisamente à presença de espírito e a desenvolver no momento a arte das combinações (DUFLO, 1999. p. 25-26).

Em ambos os casos, o jogo é o meio para uma finalidade externa, em geral, atitudinal. Considerar o jogo enquanto atividade autônoma só será possível, seguindo a argumentação de Duflo, a partir de Schiller, mas mais especificamente com o pensamento de Huizinga.

A pesquisa que ora se encaminha segue esta trilha: assumir a especificidade do jogo no âmbito das atividades humanas, seu caráter autônomo, que abre um espaço comum frágil, mas compartilhado. Ao considerar o lúdico em sua seriedade, expressa em uma configuração de significação a partir de regras específicas, os jogos permitem um campo a ser explorado pela própria prática dos participantes. No interior de regras específicas, e não para além delas, exploram-se as possibilidades de ação, que podem ser engenhosas e inesperadas. Deixar-se obedecer pelas regras não implica a dissolução dos participantes, mas garante um tipo específico de liberdade de se orientar nesta configuração, uma liberdade lúdica. E, se o ponto 
de partida é pensar o ensino de filosofia como uma experiência orientada pelos problemas conceituais herdados, o jogo (em seu uso não instrumental e resguardando sua seriedade) pode ser uma via para a abertura dessa experiência, ressignificada em um espaço compartilhado.

Neste sentido, os conceitos taylorianos aqui expostos também são importantes para o ensino de filosofia. Primeiro, para um melhor esclarecimento acerca da relação entre espaço e propósitos comuns, bem como a ideia de comunidade subjacente a ela: não é atomista e tampouco instrumental. Significa que a partir do jogo é possível explorar esta rede que se estabelece na interação entre os envolvidos. Decerto, ela dependerá do nível maior ou menor de complexidade do próprio jogo: preparar um dominó para reconstruir a argumentação conceitual de determinado pensador será diferente da elaboração de jogos cujas mecânicas incorporam a experiência de se apropriar de determinados conceitos, tais como - mas, não somente - narrativas de RPG. Quanto maior a imersão, mais fascinante será a reafirmação dos laços entre os participantes. De todo modo, em ambos os exemplos, o sentido da atividade é inseparável de sua experimentação, pois suas ações naquele momento determinado bastam a si mesmas.

Em segundo lugar, o exercício de articulação é importante neste processo, pois é por ele que as ações são repensadas e reformuladas, promovendo o novo, ao explorar as bordas do círculo mágico. Concomitantemente, abre caminho para se pensar a filosofia desde uma prática conceitual, inseparável de uma experiência autobiográfica, mas sempre inserida em um espaço comum. Isto é particularmente significativo quando tal experiência é vivenciada através da produção coletiva de conhecimento, como desenvolvida no projeto "A filosofia na construção de jogos".

Se tais relações forem válidas, pode-se pensar tanto a atividade lúdica sem um trato instrumental, conduzida para facilitar a aquisição de certos conteúdos, quanto ensaiar uma aproximação entre a atividade de jogar e a prática filosófica. Decerto, tal como a articulação, é uma tentativa que sempre corre o risco de falhar. Entretanto, disso não se segue que é um caminho a ser abandonado.

\section{Considerações finais}

A prática com jogos no ensino médio promoveu uma reflexão sobre o seu uso filosófico. Com isso, almejou-se dar um tratamento ao jogo a partir da filosofia, não 
restringindo seu uso a uma mecânica diferenciada para a transmissão de conteúdos. Isso significa pensar a atividade do jogo na dinâmica da filosofia em sala de aula. Mais do que despertar o uso lúdico no processo de ensino-aprendizagem, busca-se compreender a prática do jogo também em sua dimensão filosófica, especialmente no trabalho com o ensino médio.

As abordagens de Huizinga e de Taylor, aqui analisadas, são o ponto de partida para a construção desta pesquisa. Tanto a estrutura dos jogos, proposta pelo primeiro autor, quanto os conceitos elencados no pensamento do segundo permitem uma maior aproximação entre o jogo e a filosofia. Decerto, caso esta relação se mostre pertinente, a utilização dos jogos no ensino médio poderá ter um caráter efetivamente filosófico em seus diferentes usos na sala de aula: seja na produção coletiva de conhecimento, seja como forma de avaliar a apropriação conceitual. Como é uma pesquisa em andamento, algumas discussões precisarão ser mais bem detalhadas: as relações possíveis entre a experiência significativa do jogo e a apropriação conceitual, bem como a delimitação de uma liberdade lúdica e seu papel para se pensar o ensino-aprendizagem enquanto prática compartilhada e produção coletiva. O esclarecimento de tais considerações depende, assim, tanto do andamento da análise conceitual sobre o lúdico quanto da continuação da experiência com jogos nas aulas de filosofia.

\section{Referências:}

CAILLOIS, Roger. Os jogos e os homens: a máscara e a vertigem. Lisboa: Cotovia, 1990.

DETERDING, Sebastian et al. "Gamification: using game design elements in non-gaming contexts". In Conference on human factors in computing systems, Vancouver, 2011. p. 14. Disponível em <http://gamificationresearch.org/wp-content/uploads/2011/04/01-DeterdingSicart-Nacke-OHara-Dixon.pdf>. Acesso em maio de 2017.

DUFLO, Colas. Jouer et philosopher. Paris: PUF, 1997.

O jogo: de Pascal a Schiller. Porto Alegre: Artes Médicas, 1999.

HUIZINGA, Johan. Homo ludens: o jogo como elemento da cultura. São Paulo: Perspectiva, 2012.

LARROSA, Jorge. Tremores: escritos sobre experiência. Belo Horizonte: Autêntica, 2016.

PORTA, Mario Ariel González. A filosofia a partir de seus problemas: didática e metodologia do estudo filosófico. 4. ed. São Paulo: Edições Loyola, 2014.

TAYLOR, Charles. What is human agency?. In Philosophical papers. v. 1. Cambridge: Cambridge University Press, 1985. p. 15-44.

A política liberal e a esfera pública. In Argumentos filosóficos. São Paulo: Loyola, 2000. p. 275-304. 